\section{O papel da mídia na construção social do risco: o caso Adrianópolis, no Vale do Ribeira}

\section{The role of the media in the social construction of risk: the Adrianópolis case in Ribeira valley}

Gabriela Marques Di Giulio

Doutoranda do Núcleo de Estudos e Pesquisas Ambientais (Nepam) / Instituto de Filosofia e Ciências Humanas / Universidade Estadual de Campinas (Unicamp) gabrieladigiulio@yahoo.com.br

Newton Müller Pereira

Professor do Departamento de Política Científica e Tecnológica / Instituto de Geociências / Unicamp newpe@ige.unicamp.br

Bernardino Ribeiro de Figueiredo

Professor do Departamento de Geologia e Recursos Naturais / Instituto de Geociências / Unicamp

berna@ige.unicamp.br

Instituto de Geociências - Universidade Estadual de Campinas R. João Pandiá Calógeras, 51 13083-870 Campinas - SP - Brasil

Recebido para publicação em março de 2007. Aprovado para publicação em fevereiro de 2008.
DI GIULIO, Gabriela Marques; PEREIRA, Newton Müller; FIGUEIREDO, Bernardino Ribeiro de. O papel da mídia na construção social do risco: o caso Adrianópolis, no Vale do Ribeira. História, Ciências, Saúde Manguinhos, Rio de Janeiro, v.15, n.2, p.293-311, abr.-jun. 2008.

Resumo

Analisa a influência da mídia na construção social do risco, a partir das diferentes percepções e atitudes de moradores de uma comunidade exposta à contaminação por chumbo. O estudo contemplou análise documental e pesquisa de campo com o objetivo de compreender o papel da mídia no processo de amplificação social do risco nesse caso e observar como as respostas a uma situação de risco interagem com processos psicológicos, sociais, institucionais e culturais. Além da influência direta da mídia, este estudo de caso revelou a incidência de outros fatores a moldar as percepções do risco da comunidade, como a falta de confiança nas instituições e nos políticos, a relação do risco com as atividades ocupacionais e os valores culturais e sociais.

Palavras-chave: mídia, risco, contaminação de chumbo, Adrianópolis (PR); Brasil.

\section{Abstract}

This article analyzes the influence of the media on the social construction of risk, from the different perceptions and attitudes of the residents of a community exposed to lead poisoning. The study used a combination of documental analysis and field research to build up an understanding of the role the media had taken in the social amplification of risk in this particular case and to observe how the responses to a situation of risk interacted with psychological, social, institutional and cultural processes. Aside from the direct influence of the media, this case study reveals the importance of other factors in molding the community's risk perceptions, such as a mistrust of institutions and politicians, the relationship between risk and work activities and cultural and social values.

Keywords: media, risk, lead poisoning, Adrianópolis (PR); Brazil. 
Gabriela Marques Di Giulio, Newton Müller Pereira, Bernardino Ribeiro de Figueiredo

S egundo dados do Ministério da Saúde, até o ano de 2005 haviam sido registradas no Brasil 703 áreas com populações sob risco de exposição a solo comprometido por diferentes tipos de contaminantes (Brasil, 2005). Essa informação, além de chamar a atenção para a importância de conhecer os riscos ambientais e tecnológicos aos quais está exposta a população brasileira, demonstra como os estudos sobre riscos tornaram-se relevantes para uma análise da vulnerabilidade das sociedades contemporâneas.

Adrianópolis, município paranaense localizado na região do Vale do Ribeira, é uma das áreas no Brasil onde foram constatadas contaminação ambiental e exposição humana ao chumbo (Paoliello et al., 2002, 2003; Cunha et al., 2005; Figueiredo, 2005). Essa avaliação, complementando estudos anteriores elaborados desde a década de 1970, mostrou que as atividades de produção mineral, desenvolvidas pela usina Plumbum Mineração e Metalurgia Ltda (1945 e 1995), localizada no bairro Vila Mota (zona rural de Adrianópolis), comprometeram a qualidade do meio ambiente e expuseram a população de duas comunidades de Adrianópolis a uma situação de risco.

Adrianópolis não é apenas um bom exemplo para demonstrar a necessidade de estudos relacionados à questão dos passivos ambientais, da contaminação de solo ou dos riscos com os quais as populações modernas convivem. Face à maneira como o problema repercutiu na imprensa, é também um caso que sugere reflexão a respeito do papel da mídia na amplificação da percepção e na construção social do risco.

Entende-se aqui que o risco não existe enquanto realidade independente de nossas mentes e culturas. Como propõe Slovic (1987), ele só pode ser observado e mensurado dentro de um contexto. Por isso mesmo, o risco e as respostas a uma situação de risco são entendidos como construções sociais, já que interagem com processos psicológicos, sociais, institucionais e culturais em cujo contexto a mídia cumpre um papel relevante.

$\mathrm{O}$ caso Adrianópolis evidencia as diferentes percepções existentes frente a uma mesma situação de risco e como tais percepções são moldadas pela mídia e pela incidência de outros fatores.

Estas reflexões são decorrentes de uma investigação que teve como objetivo analisar a influência da mídia na construção social do risco, a partir da identificação das diferentes percepções e atitudes de uma comunidade exposta à contaminação por chumbo. Com esta investigação buscou-se compreender como a informação transmitida pela mídia é fundamental no processo de amplificação social do risco, assim chamado o "fenômeno pelo qual os processos de informação, as estruturas institucionais, o comportamento do grupo social e as respostas individuais dão forma à experiência social do risco, contribuindo para suas conseqüências" (Kasperson et al., 2005, p.105).

\section{Antecedentes}

O município de Adrianópolis (PR) está localizado na região do Vale do Ribeira, próximo à divisa entre os estados do Paraná e São Paulo. A cidade pertence à região metropolitana de Curitiba e contava em 2007, segundo dados do último censo do Instituto Brasileiro de Geografia e Estatística (IBGE), com uma população estimada em pouco menos de sete mil habitantes residindo predominantemente na zona rural. 
O município viveu seu auge com a mineração e metalurgia de chumbo, zinco e prata, na segunda metade do século passado, principalmente com o funcionamento da usina Plumbum Mineração e Metalurgia. Após o encerramento dessas atividades, a economia do município entrou em declínio e sua população caiu pela metade, com a escassez de emprego e precariedade das condições de vida. Hoje, a base econômica do município gira em torno do funcionalismo público e das atividades relacionada à agricultura, pecuária e ao setor de comércio e serviços (Ipardes, s.d.).

A usina Plumbum, pertencente ao grupo Trevo, funcionou no período de 1945 a 1995 e operava o beneficiamento e refino dos minérios de chumbo produzidos nas minas da região ou importados de outros países. Estima-se que, durante os cinqüenta anos de seu funcionamento, foi lançada na atmosfera grande quantidade de material particulado rico em chumbo, que se depositou nos solos de áreas adjacentes. Assim, mesmo transcorridos mais de dez anos desde o fechamento da usina e das últimas minas de chumbo, ainda permanecem o passivo ambiental e o risco de contaminação das populações locais (Figueiredo, 2005).

Para avaliar as conseqüências produzidas pelas atividades de mineração, uma equipe multidisciplinar da Unicamp realizou abrangente pesquisa no Vale do Ribeira, financiada pela Fundação de Amparo à Pesquisa do Estado de São Paulo (Fapesp), de 1998 a 2005. Envolveu, entre outros estudos, avaliação da exposição humana ao chumbo em vários municípios e revelou que parte da população de duas comunidades localizadas na zona rural de Adrianópolis - Vila Mota e Capelinha - apresentava níveis médios elevados de chumbo no sangue. Os resultados não configuravam uma situação alarmante, porém $60 \%$ das amostras de sangue coletadas nessas comunidades apresentaram concentrações de chumbo superiores a dez microgramas por decilitro de sangue, aceito internacionalmente como limite máximo de normalidade (USA, s.d.). Aproximadamente 13\% das amostras apresentaram concentrações superiores a vinte microgramas por decilitro, o que já impunha a adoção de medidas de intervenção ambiental na área e acompanhamento médico (Paoliello et al., 2002, 2003; Cunha et al., 2005).

Para verificar quais eram as prováveis fontes e vias de contaminação, estudos complementares de avaliação da qualidade do ambiente foram levados a efeito e continuam sendo realizados na região. Segundo esses estudos, a fonte primária de contaminação do solo e poeira por chumbo, nas áreas peridomiciliares e intradomiciliares, foi a Plumbum, com o lançamento direto do material particulado na atmosfera. Os resultados obtidos indicaram também que vários alimentos plantados em cultivares de hortas, nos quintais das casas próximas à Plumbum, excediam os limites de concentração de chumbo estabelecidos pela legislação brasileira e, por isso, contribuíam para a contaminação desses moradores (Lamoglia et al., Sept. 2006).

Em 2001, durante a realização desses estudos em Adrianópolis, a mídia teve acesso a parte dos resultados da pesquisa (incluindo resultados de outros estudos realizados na região) e divulgou o assunto. A primeira matéria foi apresentada no Jornal Nacional, da TV Globo, um dos noticiários mais assistidos pelos brasileiros. Entre frases como "Foram 25 anos respirando o ar pesado dentro da mineradora. O metalúrgico Olivado Fagundes ainda lembra dos sintomas da contaminação pelo chumbo: cansaço físico, formigamento 
no corpo e cor pálida" e "Crianças entre dois e doze anos que moram em bairros próximos à mineradora fizeram exames de sangue e 70\% delas estão contaminadas", a notícia chamou a atenção para o problema do município e pautou os demais veículos de comunicação, que em março de 2001 divulgaram diversas reportagens sobre o caso. Inadvertidamente, Adrianópolis passou a ser conhecida como Cidade do Chumbo.

\section{Aspectos metodológicos}

Para alcançar os objetivos desta pesquisa foi adotado um roteiro metodológico que contemplou o cruzamento de informações provenientes de duas fontes: pesquisa documental e pesquisa empírica com base em entrevistas. Os dados obtidos foram confrontados com o que propõe a literatura especializada sobre risco, avaliação, gerenciamento, percepção e comunicação de risco, e sobre divulgação científica e midiática.

Para a pesquisa documental analisaram-se notícias veiculadas entre fevereiro e março de 2001 - período em que o problema da contaminação por chumbo em Adrianópolis foi amplamente divulgado pela mídia - em material coletado e arquivado pela equipe de pesquisadores da Unicamp. São três notícias veiculadas em três mídias de prestígio nacional - Jornal Nacional, Gazeta Mercantil e Cruzeiro do Sul - e 21 notícias publicadas em dois jornais do estado do Paraná, Gazeta do Povo e Folha de Londrina, que realizam cobertura de prestígio regional e local. Dessas notícias, 16 foram veiculadas no jornal Gazeta do Povo (jornal de maior tiragem do estado, com sede em Curitiba) e cinco, no jornal Folha de Londrina.

Considerou-se a análise de conteúdo como uma técnica de investigação cujas finalidades são a descrição objetiva, sistemática e qualitativa do conteúdo manifesto em comunicação (Bardin, 1977). Na análise das notícias, obsevaram-se três itens, que evidenciam as características das matérias, mostram mudanças na mensagem jornalística com o passar do tempo e facilitam a compreensão sobre o modo de divulgação do caso: (a) a contaminação alcança a esfera pública; (b) a contaminação alcança a esfera política; e (c) o caso de contaminação e a tentativa de minimizá-lo.

Para a pesquisa empírica de campo foram realizadas três visitas a Adrianópolis: as duas primeiras em 2005, quando foram feitas observações sobre a experiência a ser estudada, e a última em 2006, dedicada à realização das entrevistas programadas. Nas visitas de 2005, foi possível acompanhar o processo de comunicação e a relação estabelecida entre pesquisadores e moradores locais. Ademais, as visitas proporcionaram um primeiro esboço dos possíveis atores sociais que poderiam ser entrevistados e, dessa forma, colaborar com a pesquisa. Com base nesses primeiros contatos estabelecemos cinco categorias sociais ou grupos de entrevistados: moradores; autoridades ou funcionários de órgãos públicos (municipais e estaduais); ex-funcionários da Plumbum; jornalistas; e pesquisadores (de áreas de meio ambiente e saúde pública). Tais grupos foram definidos, sobretudo, a partir do cruzamento de dados reunidos informalmente nas conversas com moradores e funcionários municipais e das informações obtidas durante as visitas. Vale ressaltar que, após as entrevistas, tais categorias sociais se mostraram válidas, já que os depoimentos, aliados às informações e percepções alcançadas anteriormente, reforçaram a idéia inicial de agrupar os entrevistados de acordo com as suas ocupações, responsabilidades, formas de atuação durante a pesquisa 
da Unicamp e suas diferentes percepções do risco, influenciadas também pela divulgação do caso pela mídia.

Em abril de 2006 a pesquisa de campo em Adrianópolis envolveu entrevistas com oito moradores: uma diretora de escola e um professor, que não pertenciam a nenhuma associação e acompanharam de perto as pesquisas realizadas na região; quatro autoridades municipais, que ocupavam, à época, os cargos de vice-prefeito, secretário da saúde, vereador e secretário de meio ambiente e agricultura (com exceção do secretário da saúde, então recém-transferido para Adrianópolis, os demais residiam há mais de duas décadas no município e acompanharam o apogeu e o fechamento da Plumbum, bem como a realização das pesquisas na região); e dois ex-funcionários da Plumbum (um que trabalhou como feitor na Plumbum entre 1951 e 1979 e morador da Vila Mota há 25 anos, identificado como ex-funcionário A, e outro que trabalhou na mina de 1973 a 1981 e no forno de fundição de 1985 a 1995, identificado com ex-funcionário B; ambos aposentados).

As entrevistas (com perguntas semi-estruturadas) permitiram conhecer como essas pessoas foram informadas sobre a contaminação de chumbo no local, quais eram suas percepções do risco, como foi a relação com os pesquisadores durante e após os estudos efetuados, as ações propostas (as que foram e não foram cumpridas) e como analisavam a atuação da mídia ao divulgar o caso e as repercussões dessa divulgação. Todas as entrevistas foram gravadas, com exceção daquela realizada com o vereador, já que seu depoimento surgiu espontaneamente durante uma conversa. No entanto, como o relato foi considerado revelador e importante para os objetivos do presente trabalho, ele foi posteriormente anotado e utilizado.

Além das entrevistas, foi possível ampliar as percepções a respeito do caso Adrianópolis com a visita em duas escolas municipais, na mesma ocasião. Em tais visitas exibiu-se um vídeo documentário sobre a cidade, após o que os moradores, professores e alunos presentes puderam expor suas dúvidas e curiosidades a respeito do problema da contaminação, o que colaborou muito com a pesquisa, pois foi possível verificar de forma mais ampla as percepções de risco por parte da população local.

Ainda em 2006 (julho) foi feita também uma visita a Curitiba, para entrevistar os jornalistas que cobriram o assunto em 2001, quando o caso Adrianópolis se tornou conhecido nacionalmente. Um deles, a partir de agora identificado como jornalista A, trabalhava no jornal Gazeta do Povo em 2001, cobrindo as áreas de saúde e geral. Reside atualmente nos Estados Unidos e já foi laureado com o Prêmio Esso de Reportagem. A entrevista com ele foi feita por telefone, com base em perguntas semi-estruturadas. O jornalista B trabalhava no jornal Folha de Londrina em 2001, cobrindo a área de geral. É mestre em sociologia, doutor em ciências políticas e atualmente é professor de uma universidade. $\mathrm{O}$ jornalista $\mathrm{C}$ trabalhava no jornal Gazeta do Povo em 2001, produzindo matérias sobre a área de saúde. Hoje é empresário na área de comunicação social (assessoria de imprensa). As entrevistas com esses profissionais da mídia permitiram que eles pontuassem suas impressões a respeito da divulgação do caso e de suas repercussões, bem como apontassem possíveis falhas e acertos durante a realização do trabalho jornalístico.

Também em Curitiba foi realizada uma entrevista com o ex-vice-prefeito de Adrianópolis, residente em Adrianópolis desde 1985, que acompanhou de perto os principais acontecimentos e deu suporte aos pesquisadores da Unicamp durante seus estudos na 
região. Na entrevista ele relatou suas impressões sobre a divulgação feita pela mídia, a relação com os pesquisadores e as medidas legais que foram tomadas na época, tal como a abertura de uma ação civil pública.

Foram ainda realizadas entrevistas com três profissionais ligados à Secretaria de Saúde do Paraná: um tecnólogo, uma médica da Divisão de Zoonoses e Intoxicação e uma bióloga, chefe da Divisão de Zoonoses e Intoxicação. As entrevistas tiveram como objetivos obter informações sobre o caso, verificar o que vem sendo feito em Adrianópolis e tomar conhecimento sobre uma avaliação de risco que seria realizada no município. Na ocasião também foram coletadas impressões sobre o trabalho da mídia na divulgação do problema e sobre as pesquisas realizadas no município.

No decorrer de 2006 foram entrevistados ainda seis pesquisadores das áreas de ambiente e saúde que participaram dos estudos realizados em Adrianópolis. Os três pesquisadores da área ambiental (identificados como geólogo A, geólogo B e geóloga) atuam no Serviço Geológico do Brasil (SGB/CPRM) de São Paulo. Da área da saúde, uma pesquisadora é toxicologista e trabalha na Universidade Estadual de Londrina (UEL), outra é química do Instituto Adolfo Lutz e um é médico, doutor em saúde coletiva e trabalha na Faculdade de Ciências Médicas da Unicamp. Tais entrevistas aconteceram em Campinas e em São Paulo e tiveram por propósito compreender o que aconteceu em Adrianópolis, em 2001, e reconhecer como esses pesquisadores entendem o papel da mídia na amplificação social do risco e nas percepções de risco da comunidade. A lista dos entrevistados desta pesquisa é mostrada no Quadro 1.

Quadro 1

\begin{tabular}{|ll|}
\hline Grupos & Entrevistados \\
\hline Moradores & $\begin{array}{l}\text { diretora de escola professor vice-prefeito de Adrianópolis secretário } \\
\text { local da saúde vereador secretário local de meio ambiente e agricultura } \\
\text { ex-vice prefeito de Adrianópolis ex-funcionário da Plumbum A } \\
\text { ex-funcionário da Plumbum B }\end{array}$ \\
\hline $\begin{array}{l}\text { Autoridades ou funcionários } \\
\text { de órgãos públicos } \\
\text { (municipais e estaduais) }\end{array}$ & $\begin{array}{l}\text { vice-prefeito de Adrianópolis secretário local da saúde vereador } \\
\text { secretário local de meio ambiente e agricultura ex-vice-prefeito de } \\
\text { Adrianópolis tecnólogo da Secretaria Estadual de Saúde médica da } \\
\text { Divisão de Zoonoses e Intoxicação da Secretaria Estadual de Saúde } \\
\text { bióloga, chefe da Divisão de Zoonoses e Intoxicação da Secretaria } \\
\text { Estadual de Saúde }\end{array}$ \\
\hline Ex-funcionários da Plumbum & ex-funcionário da Plumbum A ex-funcionário da Plumbum B \\
\hline Jornalistas & jornalista A jornalista B jornalista C \\
\hline $\begin{array}{l}\text { Pesquisadores } \\
\text { (meio ambiente e saúde) }\end{array}$ & $\begin{array}{l}\text { geólogo A (SGB/CPRM) geólogo B (SGB/CPRM) geóloga (SGB/CPRM) } \\
\text { toxicologista, da Universidade Estadual de Londrina (UEL) química, do } \\
\text { Instituto Adolfo Lutz médico, da UNICAMP }\end{array}$ \\
\hline
\end{tabular}

\section{Análise das notícias}

A seguir são apontados os principais resultados obtidos na análise de conteúdo das notícias, conforme as categorias mencionadas anteriormente.

A contaminação alcança a esfera pública

O problema da contaminação por chumbo chegou à esfera pública com a divulgação do caso pelo Jornal Nacional, na noite de 28 de fevereiro de 2001, e das notícias divulgadas 
em jornais de circulação nacional e regional. A primeira notícia divulgada no jornal Gazeta do Povo, em 1ำ de março, utilizou como título "70\% das crianças de Adrianópolis estão intoxicadas", já evidenciando a divulgação de dados imprecisos e em contradição com os resultados dos estudos posteriormente publicados. Nas primeiras matérias divulgadas adotaram-se palavras e expressões que contribuíram para o alarme criado em torno do caso e para a rotulação dos moradores da cidade como 'chumbados'. Os termos e expressões mais freqüentes foram: intoxicação, moradores contaminados, caipiras, "perdida nos cafundós do Vale do Ribeira", "consumindo as entranhas", caça-chumbo, bugres de Adrianópolis, "caçada aos chumbosos", vítimas, debilidade mental, alarmantes, abortos, aberrações cromossômicas, extremamente graves, sob ameaça, estado de alerta, material tóxico, chumbado, impotência sexual, envergonhados, susto.

As primeiras notícias divulgadas também apontaram que, segundo estudos feitos na região paralelamente aos da Unicamp, solo, animais e água de rios próximos de Adrianópolis estavam contaminados por chumbo. Frases como "a Secretaria Estadual de Meio Ambiente reconhece que a situação de Adrianópolis é de graves proporções" revelam um tom alarmista, assumido, num primeiro momento, tanto por órgãos de governo como pelos primeiros depoentes e transmitido e amplificado pelos jornais que divulgaram notícias sobre o caso.

O problema da contaminação também alcançou a esfera pública com a apresentação de informações contraditórias divulgadas por especialistas, poder público e mídia. No dia 3 de março, por exemplo, o jornal Gazeta do Povo publicou matéria com a informação de um médico toxicologista, pesquisador da Unicamp, mostrando que a situação parecia não ser tão alarmante como levavam a crer as informações divulgadas pelo Jornal Nacional e pelo próprio jornal paranaense. "Não é um nível de contaminação alarmante sob o ponto de vista clínico. ... Segundo ele [o médico], nenhuma das oito crianças que apresentaram os maiores índices de chumbo apresentaram problemas graves de saúde. Existem outros problemas, como os socioeconômicos, que podem estar associados à desnutrição da maioria dessas crianças". A matéria rebatia informações apresentadas pelo Jornal Nacional, ao expor uma informação dada pelo médico: "Algumas crianças apresentam anemia, mas segundo o médico, o problema também não pode ser associado ao chumbo. Ele afirma que não existem, na literatura médica, estudos que apontem o chumbo como causador de problemas no crescimento das crianças. Há uma hipótese de que isso ocorreria, se os índices de contaminação fossem mais de 20 vezes acima do tolerável pela OMS". Também reproduzia um comentário feito por uma toxicologista, integrante da pesquisa da Unicamp: "todas as regiões estudadas apresentaram níveis de chumbo no sangue dentro dos limites aceitáveis para crianças, com exceção de Vila Mota e Capelinha". No box, ao lado da matéria, outro dado contestava a informação publicada no mesmo jornal, no dia $1^{\circ}$ de março, a de que a água consumida pela população dessas vilas não estava contaminada.

\section{A contaminação alcança a esfera política}

Em 5 de março, o jornal Gazeta do Povo mostrou o envolvimento político que caracterizou o caso e como o problema da contaminação por chumbo alcançou a esfera política. A notícia, intitulada "Governo começa a atender prováveis vítimas das mineradoras", trazia em 
destaque a frase "Poluição - Instituto Ambiental do Paraná irá avaliar os reflexos dos resíduos do chumbo ao ambiente de Adrianópolis", e informava: "Esta semana, o Laboratório Central de Saúde Pública também colhe amostras de chumbo nas empresas". A matéria mostrou as contradições envolvidas no caso, assinalando que a Secretaria Estadual de Meio Ambiente "reconhece que ainda é cedo para se avaliar os danos causados pelo resíduo de chumbo em Adrianópolis" e que "pesquisas feitas por universidades paulistas apontam para a possibilidade de crianças terem sido prejudicadas pela exposição excessiva ao produto". A matéria mencionava também que os estudos feitos na região necessitavam de comparação.

O caráter político foi reforçado na matéria do dia 7 de março do mesmo jornal, evidenciado na frase: "O vice-prefeito lembra que já foi contatado por três advogados interessados em representarem os trabalhadores em ação coletiva ou ação civil pública". Esse envolvimento também pode ser comprovado com outra notícia, divulgada posteriormente no jornal Cruzeiro do Sul. Com o título "Contaminação por chumbo causa danos irreversíveis", a matéria citou um depoimento do ex-vice-prefeito de Adrianópolis em que solicitava providências às autoridades: "As mineradoras fecharam em 1996 e foram embora levando nosso ouro, prata, demais minérios e, principalmente, nossa saúde .... . Conheço e convivo com pessoas que eram saudáveis e hoje estão cegas, têm filhos de sete anos que ainda não andam, tenho em minha família mulheres que já tiveram nove abortos e administro um município onde $80 \%$ da população está contaminada, com altos índices de chumbo na corrente sangüínea".

Em 24 de março, no jornal Gazeta do Povo, a notícia sob o título "Caso de contaminação por chumbo em Adrianópolis será examinado pelo Senado", informava que a Comissão de Assuntos Sociais do Senado deveria se pronunciar no Congresso Nacional sobre as denúncias envolvendo a contaminação por chumbo em Adrianópolis: "O senador está certo de que o caso Adrianópolis deve ter repercussão no Congresso". O jornal Folha de Londrina, na edição do dia 27 de março, trouxe a notícia "Caso de Adrianópolis pode virar uma CPI", onde afirmava que a Comissão Permanente de Meio Ambiente da Assembléia Legislativa do Paraná, que investigava os casos de contaminação por resíduos de chumbo deixados no município, ameaçara propor uma Comissão Parlamentar de Inquérito para apurar o assunto.

Vale ressaltar que outras notícias mostraram também o envolvimento da Secretaria Estadual de Saúde e do Instituto Ambiental do Paraná (IAP). É o caso, por exemplo, da matéria do dia 26 de março, veiculada no jornal Gazeta do Povo, onde se lê: "os primeiros exames da Secretaria de Saúde desmentem contaminação por chumbo. De 700 pessoas já examinadas, apenas quatro apresentaram indícios" - evidenciando a decisão, por parte da Secretaria de Saúde, de examinar os moradores das áreas contaminadas. Outra notícia de 28 de março, publicada no mesmo jornal, informava que a primeira medida concreta tomada pelo IAP, depois das denúncias sobre a contaminação ambiental de Adrianópolis, foi multar em R\$2 milhões a Companhia Brasileira de Alumínio (CBA), empresa do grupo Votorantim, por armazenar indevidamente 37 mil metros cúbicos de resíduos de chumbo.

O caso de contaminação e a tentativa de minimizá-lo

Nas notícias veiculadas no final de março de 2001, observam-se tentativas de rebater os primeiros resultados divulgados pela mídia e de minimizar o caso. Duas das três notícias 
publicadas em 26 de março pelo jornal Gazeta do Povo confirmam isso. A primeira tinha como título "Primeiros exames da Secretaria de Saúde desmentem contaminação por chumbo", complementada pelas frases "Adrianópolis - vice-prefeito admite ter alardeado o problema para chamar atenção para o município" e "De 700 pessoas já examinadas, apenas quatro apresentaram indícios".

As matérias também criticavam a forma como os pesquisadores fizeram suas pesquisas: "As revelações contidas em estudos preliminares de universidades paulistas caíram num buraco negro. Nunca chegaram aos médicos da Secretaria Estadual de Saúde. Ciumeiras do mundo profissional e picuinhas acadêmicas impediram a troca de informações". Para informar o leitor sobre como a divulgação de uma possível contaminação de chumbo mudou a vida dos moradores, o repórter escreveu: "Todos os dias, desde quarta-feira, os moradores ribeirinhos de Adrianópolis têm atendido aos magotes ao chamado desesperado de um carro de som que desfila por suas ruas empoeiradas. O carro é um Fiat 1977 todo estropiado, seu motorista convoca o povo para teste de dosagem de chumbo no sangue um sustão nos caipiras". Também eram tecidas críticas à postura do vice-prefeito da cidade. "A história do chumbo que estaria contaminando as entranhas dos sete mil habitantes do pedaço parece produto da imaginação fértil e do excesso de zelo do vice-prefeito ... . Ele é o mandarim da prefeitura. O titular ... do nanico Partido Social Liberal fugiu da crise escondendo-se em São Paulo". Abordavam-se ainda implicações da divulgação sobre a possível contaminação de chumbo, por exemplo, no meio jurídico: "Uma banca de advogados de Curitiba já está no pedaço, garimpando clientes para uma ação contra a União, última responsável pela zona em que se transformou o pedaço" (Gazeta do Povo, 26 mar. 2001)

No mesmo dia, outra matéria sobre o caso informava que a situação tinha virado motivo de piadas entre os moradores, surgidas até mesmo durante as entrevistas clínicas da equipe da Secretaria de Saúde: "os mineiros mais velhos se recusavam a admitir que alguma vez tiveram alta dosagem de chumbo: 'Eles sabem que isso provoca impotência sexual e ficam envergonhados de confessar', contou um dos pesquisadores da Secretaria de Saúde". Apontava também a desinformação da população diante dos dados contraditórios que estavam sendo divulgados: "ela levou o marido de arrasto para a fila do teste, no sábado: 'Dizem que irritação e depressão são sintomas do chumbo. Como meu marido anda muito resmungão, quero saber o que está acontecendo com ele'" (Gazeta do Povo, 26 mar. 2001).

No dia 27 de março, o mesmo jornal Gazeta do Povo trazia um depoimento do antigo dono da mina de Adrianópolis e ex-deputado José Carlos Leprevost, segundo o qual a pequena quantidade de chumbo presente no local não faria mal a ninguém: "É tudo gritaria de políticos ...". Na entrevista, ele afirmava ter planos de construir ali um parque temático e prometia provar que, na cidade, "não tem poluição, tem só estagnação econômica". Na mesma matéria, o engenheiro metalúrgico Basílio Timofiecsyk, que trabalhara durante trinta anos como gerente da Plumbum, declarava: "O que ocorre aqui no Paraná é falta de informação, alarmando a população". A matéria finalizava com uma frase do proprietário da Plumbum: "Meu avô ganhou uma concessão de mineração do presidente Getúlio Vargas. Sempre estive ligado ao lugar. Mas, do jeito que as coisas vão, 
vendo tudo pela melhor oferta. O repórter pergunta o que seria uma boa oferta? Cinco milhões de reais e te vendo tudo, me livro do abacaxi'".

No jornal Gazeta do Povo de 29 de março, uma matéria tendo em destaque a frase "Foi tudo um susto" fazia referência aos resultados negativos dos exames médicos de 11 crianças de Adrianópolis que estavam sob suspeita de contaminação: "A toxicologista ... resumiu a situação no Vale do Ribeira: 'Nós garantimos ao pessoal que ela não é catastrófica nem emergencial'. Ela alertou, porém, para a necessidade da retirada dos rejeitos da mineração de chumbo da cidade, como forma de prevenção de futura contaminação".

\section{Análise dos depoimentos}

Destacamos aqui os principais trechos das entrevistas, respeitando as mesmas categorias utilizadas para a análise das notícias, acrescidas de um item relativo à percepção dos atores entrevistados a respeito do risco de contaminação por chumbo.

\section{A contaminação alcança a esfera pública}

Observa-se que o problema da contaminação por chumbo chegou à população local a partir da realização de pesquisas na região, mas ganhou atenção, de fato, com a divulgação, na mídia, dos resultados (parciais) de um dos estudos feitos em Adrianópolis: "A Plumbum fechou e ficou aquela situação de abandono, com os rejeitos a céu aberto. Mas, até então, ninguém imaginava que houvesse uma contaminação ... . Quando começaram as pesquisas, com o pessoal da Unicamp, a gente começou a ficar mais alerta. Até então, não havia divulgação ..." (moradora, diretora de escola).

Conforme relatos dos entrevistados, a mídia usou um tom sensacionalista na abordagem do assunto e ampliou um problema tido como local (apenas parte da população das comunidades de Vila Mota e Capelinha tinha índices mais altos de chumbo no sangue) para toda a cidade:

Não tivemos o cuidado de dizer que o problema não era em toda a cidade de Adrianópolis. Mas agimos com a seguinte idéia: o problema era de contaminação de água por chumbo, e o rio Ribeira passava por toda a cidade. Não sei se isso é correto ou não. Mas reconheço que é um costume errado não especificar. (jornalista C)

A gente via que [as notícias] eram mais sensacionalistas, queriam alertar as pessoas que vinham para cá. Muitos dos que chegavam não queriam almoçar nem jantar aqui. Se parassem em Adrianópolis era só para descansar e olhe lá. Não queriam tomar nem água mineral; achavam que a água mineral e tudo aquilo que eles ingerissem daqui estava contaminado ... (morador, professor)

Os pesquisadores entrevistados disseram que a mídia antecipou a divulgação do problema, ao veicular resultados parciais dos estudos. Todos os entrevistados concordaram que a divulgação trouxe conseqüências negativas para o município. Entre essas repercussões está a estigmatização da cidade e de seus moradores, rotulados como 'chumbados'.

A relação com a mídia foi, desde o início, muito unilateral ... . Quando digo que foi unilateral é porque a imprensa acabou se antecipando aos resultados e à própria divulgação oficial dos dados. Ou seja, pressionou a divulgação que ainda não era planejada, somente 
tínhamos dados parciais ... . Não poderia ter acontecido essa situação de estigmatização da região, das pessoas que moram lá. (pesquisador da área da saúde, médico)

Ouvi a notícia do Jornal Nacional, achei horrível porque do jeito que foi dito só alarmou ... (pesquisadora da área da sáude, química)

Adrianópolis ficou conhecida como a Cidade do Chumbo. Todos pensavam que aqui só tinha contaminação, que todos estavam contaminados ... . Outro dia, meus colegas de Curitiba disseram: 'Fica mais longe de nós, porque não queremos ser contaminados também'. Isso dá vergonha na gente. Os jornais vêm aqui, entrevistam as pessoas e passam matérias falando de Adrianópolis para o Brasil todo. Isso fez muito mal para a cidade. (vereador)

Hoje, a cidade ficou conhecida como Cidade do Chumbo, mas com uma visão negativa. Acredito que a repercussão do caso foi negativa para a cidade, porque mostrou ... a ganância do ser humano, o uso da ignorância dos menos esclarecidos, mostrou que quem pode fazer alguma coisa, ou seja, o poder público federal e estadual, não faz, porque isso não traz votos; os moradores de Adrianópolis são insignificantes para essas pessoas. O próprio Poder Judiciário não toma uma decisão .... . A Justiça só andou por causa da mídia ... (ex-vice-prefeito)

Os jornalistas entrevistados e que cobriram o caso em 2001 revelaram suas motivações para a cobertura do assunto e as repercussões que ela trouxe à cidade.

Fui pautado para cobrir o caso de Adrianópolis porque cobria a área de saúde no jornal .... . O assunto nos chamou a atenção porque se tratava de uma área de risco, com pessoas sob o risco da contaminação de chumbo ... . Foi praticamente um mês de notícias quase diárias .... Divulgávamos cada novidade sobre o caso ... . Até aquele momento, o editor nos cobrava matérias, mesmo que não houvesse notícias ... (jornalista C)

como eu trabalhava, na época, na editoria geral do jornal e cobria matérias sobre meio ambiente e saúde, mas sempre com um enfoque no impacto humano, as notícias de Adrianópolis foram objetos do noticiário ... . A notícia encaixava no nosso perfil: tinha interesse humano e as pessoas mais suscetíveis naquela situação eram crianças. E vamos confessar: os jornalistas gostam disso e tais assuntos vendem mais. (jornalista B)

Como o jornal Gazeta do Povo é o de maior circulação no estado do Paraná, a repercussão do assunto foi grande. As pessoas ficaram amedrontadas, na época, com a situação. Algumas delas não acreditavam numa contaminação por chumbo. Acredito que algumas pessoas deram entrevistas com a idéia de serem indenizadas, de entrarem com um processo ... (jornalista C)

Economicamente, os impactos foram negativos. Me lembro dos moradores que se queixavam que não conseguiam mais vender banana, leite. No princípio, eles achavam que a divulgação do caso era positiva, achavam que iam reabrir a indústria e que a cidade iria melhorar ... . Acho que a cobertura, de um certo modo, foi muito exagerada e sensacionalista. (jornalista B)

A cobertura do caso Adrianópolis seguiu o que a mídia diária faz normalmente: uma cobertura fragmentada e não aprofundada. Como regra, a cobertura foi baseada no apelo humano, embora tivéssemos acesso aos pesquisadores. Entendo que era preciso falar mais com os pesquisadores, ler os relatórios e fazer uma cobertura mais técnica sobre o assunto. (jornalista B)

\section{A contaminação alcança a esfera política}

Os depoimentos coletados ilustram a politização em torno do caso e mostram como o problema alcançou, de fato, a esfera política. Segundo os relatos, foi uma autoridade local quem procurou a mídia, após tomar conhecimento dos estudos que eram feitos na região. 
Quando fui candidato a vice-prefeito, em 1996, perdemos as eleições, mas comecei a perceber, na campanha de casa em casa, que na Vila Mota havia um número grande de pessoas cegas ... . Também me chamou a atenção o maior número de pessoas com retardamento mental na Vila Mota. Por coincidência, li artigo sobre o chumbo que dizia que ele levava à impotência sexual, degeneração dos órgãos e que, entre os malefícios causados pelo chumbo, um deles era a cegueira. Associei então o problema da Vila Mota com a cegueira. Na época, tentei buscar ajuda e informação junto à Secretaria de Saúde do Estado, mas, como não ocupava cargo algum, não consegui .... . Entre 2000 e 2001, conheci o pessoal de uma universidade que fazia pesquisas em Adrianópolis; aquilo me chamou a atenção. A empresa [Plumbum] já tinha fechado há cinco anos .... Chegou num ponto que percebi que ninguém estava interessado, os verdadeiros responsáveis não estavam interessados. Foi aí que resolvi procurar a imprensa. Fiz contato com a afiliada da TV Globo no Paraná, e a primeira notícia sobre o caso circulou no Jornal Nacional. Através da imprensa é que deu a explosão das notícias ... (ex-vice-prefeito)

Somente com a divulgação no Jornal Nacional é que a Secretaria de Saúde do Paraná tomou ciência do problema de Adrianópolis e de uma das pesquisas que aconteciam na região. A partir de então, o órgão tomou as primeiras medidas efetivas para avaliar o problema no município, a exemplo da realização de coleta e análise de sangue dos moradores, de alimentos, solo e água de Adrianópolis.

Em relação à pesquisa da outra universidade, tivemos conhecimento depois que a Rede Globo divulgou uma matéria sobre crianças que estariam recebendo das nutricionistas doses de quelante, um medicamento que tem o papel de retirar o chumbo do sangue, mas que deve ser usado somente em casos mais graves de intoxicação. A partir daí buscamos, junto ao Comitê de Ética dessa universidade, o projeto e sua aprovação, mas até hoje não tivemos um retorno. (chefe da Divisão de Zoonoses e Intoxicação)

Naquele ano [em 2001], a Secretaria fez uma avaliação, mas não se conhecia a metodologia de avaliação de risco da ATSDR [Agency for Toxic Substances and Disease Registry]. Somente agora [em 2006] o Ministério da Saúde começou a fazer avaliações seguindo essa metodologia. Em 2001, a avaliação contou com a participação, além da Secretaria de Saúde, das Secretarias de Meio Ambiente e Agricultura. Fizemos, além da coleta de sangue para análise, coletas de alimentos, solo e água. A Saúde avaliou todas as crianças da Vila Mota e Capelinha com até 14 anos de idade ... . Na época, das mais de duzentas crianças analisadas, vinte estavam com teores de chumbo acima do nível aceitável. As que estavam com mais de vinte microgramas de chumbo por decilitro de sangue foram encaminhadas para o Hospital das Clínicas, onde passaram por uma avaliação neurológica, cujos resultados não foram conclusivos, já que estas crianças sofriam de anemia e desnutrição. (chefe da Divisão de Zoonoses e Intoxicação)

O envolvimento de políticos no caso também é confirmado por outros entrevistados.

O ex-vice-prefeito fez todo um alarme, queria entrar com um processo para as pessoas receberem indenização. Não sei se isso estava certo ou não, nunca conversei com ele para saber se essas pessoas tinham direito ou não. A Globo veio, ele deu asas para o negócio e ficou meses falando nisso. A população ficou sabendo dessa forma, bem abrupta. (vice-prefeito)

Acredito que houve a intenção da superexposição da imagem. O interesse político caminhava junto com a divulgação da situação. (jornalista C)

a CPI e a própria forma como o caso Adrianópolis foi explorado tinham uma carga política e interesse em explorar a questão ambiental ... . Acredito que foi um trabalho eminentemente político; tenho dúvida se eles tinham convicção de que se tratava de um problema ambiental. (jornalista B) 


\section{O caso da contaminação e a tentativa de minimizá-lo}

Após quase um mês de notícias sobre o problema do chumbo em Adrianópolis, houve uma tentativa de minimizá-lo que foi reproduzida e influenciada pela mídia. Esse último estágio de evolução das notícias é abordado nos depoimentos seguintes.

Em relação à imprensa, o que surpreendeu mais foi o jornal Gazeta do Povo, que é o de maior circulação no estado. Tinha um repórter que sempre me procurava e que acompanhou o caso desde o início. Noticiava com responsabilidade e transparência tudo o que via ... . Aí, de repente, apareceu um outro repórter do jornal e eu, inocente, acreditei nele. Um dia ele apareceu por lá, fez várias perguntas, falou com um médico que estava lá .... E saiu a matéria, uma página inteira: nada do que este jornalista viu, ele colocou na reportagem; ele escreveu uma história da cabeça dele ... . Acho que a matéria foi comprada. (ex-vice-prefeito)

Eu disse para o diretor do jornal que achava que aquela história [de contaminação por chumbo] não era bem assim, que queria trabalhar no caso. Fui contra a corrente, dizia que o assunto deveria ser melhor checado e que era preciso investigar ... . O ex-vice-prefeito não tinha nenhum know-how para falar do assunto. Era um homem do povo, que não sabia nada. Mas é mais fácil espalhar que todo mundo está morrendo do que dizer que isso não é verdade. (jornalista A)

Após um mês de notícias diárias sobre o caso, o jornalista A encerrou o assunto para o jornal dizendo que a única pessoa chumbada era quem havia levado um tiro ... . Com essa matéria dele, o jornal pôs um ponto final mesmo, como se aquilo tudo que foi feito e noticiado antes não existisse mais ... . A Gazeta entendeu que não era mais para falar sobre chumbo em Adrianópolis e encerrou as notícias. (jornalista C)

Quando a divulgação do risco de contaminação por chumbo passou a representar um problema aparentemente maior do que conviver com esse risco, em face de todas as repercussões trazidas pela divulgação midiática, parece ter ocorrido um esforço, principalmente por parte das autoridades locais, para retornar à vida cotidiana e promover o esquecimento do problema, como mostram os depoimentos a seguir.

Se não tem solução para o problema, então não vem pesquisar. Eu respeito o trabalho de vocês [pesquisadores]. Tenho um filho que também está na faculdade, não tenho nada contra vocês. Mas vêm aqui, pesquisam e não fazem nada. As coisas para nós só pioraram. (vereador) os atuais donos da Plumbum começaram a se preocupar com a questão ambiental e estão completando o projeto de recuperação dos danos ambientais, cobrindo os rejeitos e resíduos cobertos com terra vegetal. Com isso resolve-se o problema. O chumbo é um material inerte. Quanto à escória, havia problema de poluição visual, devido a sua poeira. Colocando os dois materiais juntos e colocando cobertura de terra e grama, está resolvido o problema. (secretário de Ambiente e Agricultura)

Eles fizeram os aterros, não é o que me contentaria, porque não é um aterro de classe 1, monitorado, como deveria ser. Fizeram um aterro simples. Gostaria que o lugar de lá fosse tratado como qualquer outro local mais visível, como em Curitiba, São Paulo. (ex-viceprefeito)

Acho que alguma coisa a mais do que eles estão fazendo deveria ser feito. Ainda falta a conscientização do povo daqui para que se possa cobrar. (morador, professor)

Percepções do risco

Os depoimentos demonstram como as percepções do risco de contaminação por chumbo foram moldadas pela divulgação do problema feita pela mídia, pelas informações contraditórias 
apresentadas e pelo envolvimento político que caracterizou o caso. Também influíram questões relativas à legitimidade (ou ausência desta) das instituições envolvidas na avaliação e gestão do risco, já que houve a quebra de confiança de um sistema perito (representado pelas universidades e pelos órgãos públicos municipais e estaduais), em virtude dos dados contraditórios e da ausência de estratégias organizadas para a comunicação dos fatos, por parte desses atores. Isso colaborou para produzir um sentimento de medo, pânico e descrença na população local. Esses sentimentos, aliados aos próprios valores (culturais e sociais) dessas pessoas, contribuíram também para as percepções que elas têm sobre o risco e para as suas atitudes.

Ficamos muito preocupados justamente com o local, com o respeito às instituições locais, com a população local ... e acabamos inconscientemente esquecendo da Secretaria de Saúde do estado. Isso foi errado e foi algo que aprendemos ... . De qualquer modo, houve um certo desrespeito, por parte da imprensa em geral, com o que estava acontecendo, e isso causou problema. Acho que serve para aprendermos a ter uma cadência diferente no contato com a imprensa. [Devemos] ter isso mais em mente. (pesquisador da área da saúde, médico)

Acho que deveria ter sido feito muito mais [sobre ações de mitigação/remediação]. Não sei se a Secretaria de Meio Ambiente está envolvida no caso, mas tudo está muito moroso. Sei que a Secretaria de Saúde do Estado do Paraná andou tratando os doentes ... . Acho que é preciso também um trabalho de conscientização com os moradores; eles não sabem o risco, sabem que é perigoso ... (pesquisadora da área da saúde, química)

Acho que a contaminação de chumbo não traz problemas. A turma diz que traz, mas eu acho que não. Eu acho que é coisa política ... . Não sei explicar o que é a contaminação. A turma diz que quando se lida com qualquer chumbo sobe o teor no sangue. Mas na empresa tinha cara que chegava a se aposentar e nunca tinha tido problema com chumbo. Não acho perigoso ... (ex-funcionário $\mathrm{B}$ )

Vou fazer oitenta anos e passei a maior parte da minha vida aqui. A gente ficava no meio da fumaceira de enxofre, vinha do serviço, meu peito doía. Estou com oitenta anos e não sinto nada. Graças a Deus nunca tive problema de saúde .... . Acredito que muita gente que trabalhou na fábrica morreu, mas morreu porque tinha que morrer mesmo, já tinha passado o tempo dele. Mas não por veneno. (ex-funcionário A)

Ouço falar do problema da contaminação desde quando nasci. Quando a Plumbum funcionava, já se falava que os trabalhadores tinham que tomar leite em função do chumbo ... . As pessoas lá fora pensam que o município inteiro é contaminado, e nós sabemos que é só na região ... . Em todo caso, eu acho perigosa a contaminação, não moraria na Vila Mota de jeito nenhum, porque causa mal à saúde, com certeza. (vice-prefeito)

Acho que poucos moradores percebem a situação de risco. A pessoa que tem o problema na família tem vergonha e medo de falar. Sempre pensa em algum parente que trabalha na prefeitura e que pode vir a perder o emprego. É problemático, porque a cidade é pequena .... . Lamento que as pessoas de lá não tenham vontade de mudar de vida. Acho que em Adrianópolis falta às pessoas acreditarem nelas mesmas, saberem que tudo que pode acontecer depende delas. (ex-vice-prefeito)

\section{Discussão}

Ao analisar o caso Adrianópolis, é preciso pensar no próprio conceito embutido na noção de risco, geralmente associado à probabilidade de ocorrência de um dano à sociedade ou ao meio, que pode desencadear doenças e acidentes. Nesse conceito, três componentes são relevantes: potencial de perdas e danos; incerteza da perda/dano; relevância da perda/ 
dano (Fonseca et al., mar. 2007). No entanto, nos estudos sobre esse assunto é preciso considerar que o risco não existe como realidade independente de nossas mentes e culturas.

Como propõe Slovic (1987), o risco só pode ser observado e mensurado num dado contexto. Por isso mesmo, o risco e as respostas a uma situação de risco são entendidos como construções sociais, já que interagem com processos psicológicos, sociais, institucionais e culturais. Essa interação é responsável pela amplificação ou atenuação das respostas a uma situação de risco. Nesse sentido, o autor estabelece uma distinção entre probabilidade e percepção do risco. Para ele, risco real e risco percebido são duas dimensões diferentes. Beck (1999) concorda com essa visão, ao destacar que a percepção de tratamento dos riscos determina pensamento e ação. Assim, a percepção e a definição cultural constituem o risco.

A escolha dos riscos aos quais se dá maior atenção não está relacionada exclusivamente às preocupações com a proteção da saúde, da segurança e do ambiente. A escolha reflete aspectos como as crenças das sociedades acerca dos valores, instituições sociais, natureza, justiça e moral. Esses fatores são determinantes na superestimação ou subestimação de determinados riscos (Freitas, 2000). Estudos têm mostrado que, diante de novas situações que envolvem riscos, as pessoas tendem a não confiar em fatos e dados empíricos. Elas se apegam às construções simbólicas, confiam mais nas próprias crenças e convicções e dificilmente mudam de opinião (Fonseca et al., mar. 2007).

Como propõe Freitas (2000), a falta de participação direta, por parte dos interessados, no gerenciamento dos riscos e nos processos decisórios que estabelecem as estratégias dessa gestão, também contribui para a percepção que as pessoas têm sobre o risco. Além disso, a legitimidade das instituições envolvidas na gestão dos riscos, da indústria e do poder público nos seus diversos níveis (municipal, estadual e federal) também influencia no nível de preocupação de uma comunidade em relação aos riscos aos quais está exposta.

Neste sentido, o caso Adrianópolis apresenta importantes elementos que moldaram e colaboraram para as percepções do risco de contaminação por parte da comunidade local. Estes elementos reúnem:

- Informações contraditórias divulgadas por especialistas, poder público e mídia;

- Falta de confiança nas instituições envolvidas (não somente pelas informações conflitantes mas também, sobretudo, pela ausência de estratégias organizadas de comunicação, por parte dessas instituições e órgãos público,s e pela demora na implementação de ações para minimizar ou solucionar o problema);

- O risco aparentemente invisível (o risco é mais facilmente percebido se é visto; como atesta um dos depoimentos, com a remoção de rejeitos e resíduos o problema de contaminação no município parecia ter sido solucionado, quando, na verdade, o problema está na poeira e nos solos contaminados);

- O caráter político que envolveu o caso;

- A relação do risco com as atividades ocupacionais (riscos familiares como os relacionados à ocupação são mais aceitos porque são percebidos como controláveis, não ameaçadores, de conseqüências não fatais, como mostram Fonseca et al., mar. 2007);

- A ausência da comunidade na sugestão e implementação de ações para minimizar o risco (como mostram alguns depoimentos, o tipo de aterro construído em 
Adrianópolis parece não ser o melhor para o problema; há também evidência de que, por falta de informação, a população não cobra ação, o que evidencia a falta de participação pública no gerenciamento do risco);

- A necessidade de retornar à vida cotidiana e construir o esquecimento do problema.

A forma como os meios de comunicação divulga uma determinada situação de perigo influencia diretamente na percepção das pessoas e nas suas respostas e atitudes. A divulgação midiática pode ampliar ou atenuar a percepção de um determinado risco, dependendo da extensão da cobertura e da seleção dos fatos que se faz ao divulgar um acontecimento ou uma situação. É evidente que a visibilidade midiática é crucial para que os problemas ambientais deixem de ser apenas condições vigentes, com as quais a humanidade tem de conviver, para se tornarem assuntos que demandam atenção pública e devem induzir a elaboração de políticas. Sem a cobertura dos meios de comunicação social, é pouco provável que problemas antigos entrem na esfera do discurso público ou venham a fazer parte do processo político (Hannigan, 1995).

A cobertura do caso Adrianópolis contribuiu para que os moradores, assim como a sociedade em geral, tivessem maior consciência a respeito do problema e também colaborou para que ações fossem tomadas por instituições governamentais do Paraná, como a coleta e análise de sangue de moradores, alimentos, hortas e água do município, bem como o encaminhamento de alguns munícipes para tratamento médico. Entretanto, a seleção de informações que a mídia faz, ao noticiar determinado assunto, é um dos fatores de complicação no gerenciamento do risco, como indicam Covello e Sandman (2001). Geralmente as notícias dão mais atenção aos riscos que envolvem dramas, conflitos ou situações negativas. Ao agir assim, a imprensa ajuda a criar um clima de psicose coletiva (Sturloni, 2006). Sturloni observa que, na lógica da comunicação de massa, a relevância de um risco depende dos fatores de noticiabilidade do evento, como proximidade do receptor, violação de normas de conduta, presença de vítima identificada, atribuição de culpa, existência de um conflito. É preciso considerar ainda que a noção de risco é transmitida ao jornalista de diversas formas por cientistas, associações de defesa do meio ambiente, pelo cidadão comum, pelo governo, por empresas. "E, como tudo que é negativo facilmente seduz a comunicação social, nem sempre o jornalista pára para pensar o quanto o risco é ampliado, de forma intencional ou não" (Garcia, 2004).

A cobertura que a mídia faz pode, mais do que moldar a percepção do risco, colaborar para a estigmatização de pessoas, lugares, tecnologias e produtos, contribuindo assim para o processo conhecido como amplificação social do risco. O caso Adrianópolis mostra isso. A mídia, num primeiro momento, divulgou amplamente o problema, a partir da denúncia de contaminação feita por um político e morador do município e de resultados de estudos em andamento na região (parciais e não conclusivos). Por se tratar de assunto que atrai audiência - envolvendo problemas ambientais, situação de risco à saúde humana, envolvimento de crianças como principais vítimas -, os jornais tinham a incumbência de publicar notícias mesmo quando não havia nenhuma novidade, como revelou o depoimento de um dos jornalistas entrevistados.

A cobertura, na opinião de moradores, pesquisadores e também dos próprios jornalistas que cobriram o caso, foi considerada fragmentada, sem profundidade e baseada no apelo 
humano. Nesse sentido, a cobertura jornalística induziu a percepção, por parte da sociedade, de um risco aparente exagerado, como mostram os depoimentos colhidos, do tipo "as pessoas lá fora pensam que o município inteiro é contaminado e nós sabemos que é só na região". De fato, a mídia contribuiu para a amplificação social do risco e, sobretudo, para o processo de estigmatização do município e dos moradores. Nos dias seguintes à veiculação da notícia no Jornal Nacional, repórteres foram ao município para cobrir o problema. A mídia gerou interesse público extraordinário, com percepções de enorme risco aparente até mesmo entre as pessoas que não tiveram qualquer contato com o material contaminado. Prova disso são os depoimentos que abordam a dificuldade de os moradores conseguirem emprego em outras cidades, venderem seus produtos agropecuários em feiras livres e mercados, além de terem eles enfrentado, até 2006 (cinco anos após a divulgação do caso), situações de preconceito e estigma - entendendo-se estigma como a situação do indivíduo que está inabilitado para a aceitação social plena (Goffman,1982), como atributo profundamente depreciativo e como um processo de desvalorização dos sujeitos que produz iniqüidades sociais e reforça aquelas já existentes (Ayres, França Jr., Paiva, 2006).

Mais do que trazer à tona essas reflexões relacionadas à influência da mídia na construção social do risco e à incidência de outros fatores que moldam as percepções do risco, é possível perceber, a partir do caso estudado, como a dimensão social e a questão da subjetividade são fatores importantes e que devem ser considerados no gerenciamento de uma situação de risco.

Como propõe Bradbury (1989), considerar a tecnologia, o meio ambiente e o risco como resultantes de processos sociais conduz à formulação de uma nova visão de gerenciamento de risco, na qual são considerados aqueles que vivenciam de fato situações de risco, as instituições públicas e privadas envolvidas - entendidas como porta-vozes de interesses sociais, políticos e econômicos estruturados na sociedade - e os contextos sociais e culturais em que o risco é analisado e gerenciado. Nessa nova forma de gerir o risco, em que são incorporadas as percepções e atitudes daqueles que se encontram expostos aos riscos, é possível criar estratégias que possibilitem uma efetiva participação de todos os atores sociais envolvidos no processo de mitigação/remediação de situações como a de Adrianópolis. Por isso mesmo, ressalta-se a importância de estudos como o daquela cidade, que, com seu viés sociológico, é capaz de demonstrar sobretudo que o risco se vivencia no interior de cenários, onde falas, silêncios, expressões e segredos são objetos de um conhecimento coletivamente elaborado. Como pontua Freitas (2000), esse conhecimento coletivo é elaborado em contextos sociais específicos e complexos, que formam unidades pertinentes para a compreensão de como se articulam os comportamentos individuais e se constrói coletivamente a percepção de riscos, bem como diversos tipos de clivagens e conflitos que surgem no interior dessa construção comum.

\section{Considerações finais}

O caso Adrianópolis mostra claramente a influência da mídia na construção social do risco e como as respostas a uma situação de risco interagem com processos psicológicos, sociais, institucionais e culturais. Se, por um lado, a divulgação midiática colaborou 
fortemente para o processo de amplificação social do risco, por outro também contribuiu para que os moradores locais pudessem ter uma percepção e uma consciência maior a respeito do problema, assim como a sociedade em geral, incluindo as instituições governamentais que dedicaram maior assistência a algumas famílias. Vale salientar que, principalmente em 2001, a divulgação conseguiu chamar a atenção de governos, políticos e ONGs e que algumas famílias contaram, por algum período, com assistência médica e nutricional da Secretaria Estadual de Saúde do Paraná. Em 2005 o problema voltou a ser pautado pela mídia e entrou de vez na agenda da Secretaria, que começou um trabalho de avaliação de risco seguindo as normas propostas pela Agency for Toxic Substances and Disease Registry (ATSDR). Também foram tomadas providências com respeito aos resíduos industriais que estavam expostos, como a criação de um aterro.

Entretanto, como o caso mostrou, quanto maior a atenção da mídia, maior a atenção que as pessoas dão à situação de risco, o que gera interesses públicos extraordinários, com percepções de risco exageradas. No caso em estudo, a divulgação moldou as percepções de risco das pessoas, influenciou na promoção de um clima de medo e alarme na cidade e colaborou para o aumento das crenças e mitos que envolvem termos como contaminação, chumbo e intoxicação, reforçando o estigma criado em torno das pessoas e do local. Ainda que o município tenha conseguido escapar do rótulo 'Cidade do Chumbo', seus moradores ainda enfrentam problemas relacionados ao evento e temem participar de pesquisas futuras e conceder entrevistas aos veículos de comunicação.

O estudo realizado deixa evidente também que, além da influência direta da mídia, há outros fatores a moldar as percepções do risco de contaminação por parte da comunidade: informações contraditórias divulgadas por especialistas, poder público e mídia; falta de confiança nas instituições envolvidas (devido, sobretudo, à ausência de estratégias organizadas de comunicação, por parte dessas instituições e órgãos públicos, e à demora na implementação de ações para solucionar o problema); o caráter político que envolveu o caso; valores culturais e sociais da população envolvida; ausência de participação da comunidade na sugestão e implementação de ações para minimizar o risco (isto é, no gerenciamento do risco); a necessidade de retornar à vida cotidiana e construir o esquecimento do problema.

\section{AGRADECIMENTOS}

Os autores agradecem o apoio financeiro da Fundação de Amparo à Pesquisa do Estado de São Paulo (Fapesp) e do Conselho Nacional de Desenvolvimento Científico e Tecnológico (CNPq), bem como aos pareceristas que, com suas contribuições, enriqueceram este artigo.

\section{REFERÊNCIAS BIBLIOGRÁFICAS}

AYRES, José Ricardo; FRANÇA JR., Ivan; PAIVA, Vera.

Crianças e jovens vivendo com HIV/Aids: estigma e discriminação. ComCiência, n.76. Disponível em: http://www.comciencia.br/ comciencia/handler.php?section $=8$

\&edicao=13\&id=106. Acesso em: 14 ago.2006.

BARDIN, Laurence.

Análise de conteúdo. Lisboa: Edições 70. 1977.
BECK, Ulrich.

World risk society. Cambridge: Polity Press. 1999.

BRADBURY, Judith.

The Policy Implications of Differing Concepts of Risk. Science, Technology \& Human Values, Baton Rouge, v.14, n.4, Autumn, p.380-399. 1989.

BRASIL.

Ministério da Saúde. Secretaria de Vigilância 
em Saúde; Coordenação Geral de Vigilância Ambiental em Saúde. Capacitação, identificação, levantamento de informações e priorização de áreas com populações expostas ou sob risco de exposição a solo contaminado. Disponível em: http://portal.saude.gov.br/portal/arquivos/pdf/ manual_capacitacao_2007_vigisolo.pdf. Acesso em: 10 jan. 2008. 2005.

COVELlO, Vincent; SANDMAN, Peter. Risk Communication: evolution and revolution. In: Wolbarst, Anthony (Ed.). Solutions to an Environment in Peril. Baltimore: John Hopkins University Press. p.164-178. 2001.

CUNHA, Fernanda et al.

Human and environmental lead contamination in the Upper Ribeira Valley, southeastern Brazil. Terrae, Campinas, n.2, p.28-36. 2005.

FIGUEIREDO, Bernardino Ribeiro. A contaminação ambiental e humana por chumbo no Vale do Ribeira (SP-PR).

ComCiência. Disponível em: http:// www.comciencia.br/reportagens/2005/11/ 09.shtml. Acesso em 12 nov. 2005. 2005.

FONSECA, Maria da Graças Uchoa et al. Percepção de risco: maneiras de pensar e agir no manejo de agrotóxicos. Ciência \& Saúde Coletiva, Rio de Janeiro, v.12, n.1, p. 39-50. mar. 2007.

FREITAS, Carlos Machado.

A contribuição dos estudos de percepção de riscos na avaliação e no gerenciamento de riscos relacionados aos resíduos perigosos. In: Sisinno, Cristina Lucia Silveira; Oliveira, Rosália Maria de (Org.). Resíduos sólidos, ambiente e saúde: uma visão multidisciplinar. Rio de Janeiro: Fiocruz. 2000.

GARCIA, Ricardo.

Sobre a Terra: um guia para quem lê e escreve sobre ambiente público. Lisboa: Comunicação Social. 2004

GOFFMAN, Erving.

Estigma: notas sobre a manipulação da identidade deteriorada. Rio de Janeiro: Zahar Editores. 1982.

HANNIGAN, John.

Sociologia ambiental: a formação de uma perspectiva social. Lisboa: Instituto Piaget. 1995.
IPARDES.

Instituto Paranaense de Desenvolvimento Econômico e Social. Perfil municipal de Adrianópolis. Disponível em: http:// www.ipardes.gov.br/perfil_municipal/ MontaPerfil.php?Municipio $=83490$. Acesso em: 10 jan. 2008. s.d.

KASPERSON, Roger et al.

The social amplification of risk: a conceptual framework. In: Kasperson, Jeanne; Kasperson, Roger. The social contours of risk: publics, risk communication and the social amplification of risk. London: Earthscan. p.99-114. 2005.

LAMOGLIA, Talita et al.

Lead in food and soil from a mining area in Brazil and human exposure. Chinese Journal of Geochemistry, Supplementary Issue dedicated to the $7^{\text {th }}$ International Symposium on

Environmental Geochemistry, Beijing, p.66. Sept. 2006.

PAOLIELLO, Mônica Maria Bastos et al. Exposure of children to lead and cadmium from a mining area of Brazil. Environmental Research, Baltimore, v.88, p.120-128. 2002.

PAOLIELLO, Mônica Maria Bastos et al. Determinants of blood lead levels in an adult population from a mining area in Brazil. Journal de Physique IV, Grenoble, v.107, p.127-130. 2003.

\section{SLOVIC, Paul.}

Perception of risk. Science, Cambridge, v.236, n.4.799, p.280-285. 1987.

\section{STURLONI, Giancarlo.}

Le mele de Chernobyl sono buone: mezo secolo di rischio tecnológico. Milano: Editore Sironi. 2006.

USA.

United States of America. Centers for Desease Control and Prevention. Departament of Health and Human Services. Division of Laboratory Services: lead. Disponível em: http://www.cdc.gov/nceh/dls/lead.htm. Acesso em: 10 jan. 2008. s.d.

\section{$\rightarrow \rightarrow \rightarrow<<<$}

